\title{
SOCIOLINGUISTIC APPROACH TO TRANSLATION \\ PROBLEMS: IN THE EXAMPLE OF DEDE KORKUT AND \\ THE QURAN
}

\author{
Nusrat SHIKHBABAYEV \\ Azerbaijan \\ Qafgaz University \\ Faculty of Letters \\ Department of Translation \\ nshikhbabayev (at) yahoo.com
}

\begin{abstract}
$^{\mathrm{i}}$
This article aims at learning how languages influence on culture and society as a result of translators' lack of familiarity with the culture of that language properly and developing a common method regarding how to translate old languages (Arabic, Persian and Turkic languages written in Perso-Arabic script) into English correctly specifically, by determining difficulties and problems occurred when translating old languages into English and give suggestions to solve such problems based on the three different copies of the old Turkic legendary book the book of Dede Korkut, which is well known among Turkic speaking countries and which was written in Perso-Arabic script in XI-XVI centuries AD (Mirabile, 1991: 6; Shikhbabayev, 2009: 13), and The Alcoran of Mohammed translated into English directly from the original Arabic by George Sale in 1861 (Sale, 1861).
\end{abstract}

Keyword: Translation, Sociolinguistics, Dede Korkut, The Quran.

Shikhbabayev, N. (2013). Sociolinguistic Approach to Translation Problems: In The Example of Dede Korkut and the Quran. Ulakbilge, 1 (2), s.71-83. 
In order to develop a common method regarding how to translate old languages (Arabic, Persian and Turkic languages written in Perso-Arabic script) into English we decided to consider English translations of the abovementioned books. This will also assist in learning the influence of a language on the culture and society as a result of translators' lack of familiarity with the culture of that language.

Certainly, many problems are likely to occur when translating old languages into English. This is especially true of those languages that are no longer currently in use and especially true of those that have been completely forgotten. Some aspects of translation, such as accuracy or the effort to preserve the originality of source language (SL) meaning when translating into target language (TL), be it either old or modern language, has always been difficult and problematic. This is so regardless of which language you are translating to or from accept that when old languages are in Arabic or Persian or written in Perso-Arabic script, the magnitude of difficulty in translating is significantly increased.

In Arabic, Persian and Turkic languages written in Perso-Arabic script, vowels are not written in most cases. This is a type of writing system that where each symbol always or usually stands for a consonant, leaving the reader to supply the appropriate vowel while reading (Wikipedia, Abjad, 2012).

That's why we decided to raise and study this problematic issue and bring some clarification for further studies and illuminate the ways of the researchers intending to translate old languages into English. We believe that study and analysis of such translation problems and learning how misunderstanding or inaccuracies occur due to the lack of familiarity with the culture, can be useful for every researcher who is interested in translation strategies of old languages and learning consequences of mistranslation in the world community.

So, absence of vowel signs in Arabic, Persian and old Turkic languages, more precisely, writing them without vowel signs in the professional form of the language using just one vowel sign to suggest several vowel signs and make people guess which vowel sign belongs to which vowels amplify the problem. For example, the letter 'aleph' - ' I ' with a sign above in Arabic, Persian and old Turkic is used for each 'a', 'e' , 'u', 'ü' vowels, but the letter 'aleph' - ' ! ' with a sign below is used for 'i' or 'o' (neutral) vowel (Shikhbabayev, 2009: 62-63). Certainly such confusions counting the weight of the old words in those languages creates extra burden both for a reader and a translator.

We consider that translation is not the world-for-word process that is accepted by some from one language to another. Instead, we suggest that a translator should select the best 
fitting meaning of the expression based on what the translator believes to be the most correct variant of the original text.

When it comes to old languages which are completely in old or forgotten language, the difficulties and contradictions are increased exponentially for some reasons. Considering that both Dresden and Berlin manuscripts of the book of Dede Korkut were written in PersoArabic script, for that reason translators are not able to preserve all correct vocalizing of the words while reading the original. Fortunately, the third copy of the manuscript stored in the Vatican Museum was inserted with vowel signs and therefore it is much easier to understand. Accordingly, due to complexity of vowel system in the phonetic system of Arabic, Persian and as well as old Turkic languages, some translators hold themselves free and do not pay closer attention to vocalizing the consonantal text and as a result, they make serious mistakes while translating. However, all these difficulties in translation as we noted earlier is definitely connected with incorrect vocalizing. For example, the word 'ç1xdi' in old Azerbaijani-Turkic language which means 'left' (past participle verb). Researchers, O. Shaik and V. V. Bartold read it as 'chikhdi', others, M. Ergin and H. Arasli read it as 'chakhdi', unlike others S. Jamshidov, read it quite differently as 'choquddu' each of which is used in various meanings (Shikhbabayev, 2009: 63).

This is exacerbated by the fact that most words in some old languages are no longer used today. So we purposively selected some incorrectly or poorly translated words and expressions as examples from old books which dates back to XI-XVI c. AD (Mirabile, 1991: 27) written in Arabic, Persian and Turkic languages written in Perso-Arabic script and tried to reveal some mistakes in translation and their influence on culture and society.

Translation of old languages has always been a problematic and difficult issue. So therefore, let us consider some of the reasons these translations are regarded as so difficult. First, consider that before starting the translation of old languages, the translator should try to discern whether the manuscript is a copy or is the original. In the event it is a copy of the original, and the original text is extant, the translator should travel and compare the original with the copy they own. It is, of course, important that this be done early (i.e. at the beginning of study) in order to avoid errors inherent in working upon a flawed copy. This one action will save the translator many frustrations and difficulties related to the objections of others who are closer to the original text.

Copies of the manuscripts or copies of the copies may leave some difficulties or ambiguity behind, and finally cause translation of such copies to be a waste of time. In the event the original is not discovered, translators who intend to translate the old language 
should try to get all available copies of the original. Their next step is to put them together and compare all differences and similarities. After this comparison of all existing forms of copy, the difficult decision should be made as to which words or expressions in the manuscript to select as likely to be most authentic. If this is not done, many different and possibly dissimilar translations of one work may appear in future or cause some concern or confusion to readers.

Another of the most evident problems is the differences in cultural practices between the culture of the original text and the new culture for which the text has been translated. Having had such a difficulty, we think that a translator must become conversant in the cultural differences between the original language and the translated language of the text and must not ignore any cultural factors. This means that as a first step, translator must be well acquainted with the cultural and social factors of both the present and the past. Consider the following: Once the number for 'seven', 'seventy', and 'seven hundred' in old Arabic and old Turkic had been used to denote quantifiers like 'many or much' (Hatip, 1999: 27). However, today, this word is no longer used for that reason. Let's see similar examples in the book of Dede Korkut and the Koran:

a) 'It is he who has created for you whatsoever is on earth, and then set his mind to the creation of heaven, and formed it into seven heavens; he knows all things.' (Sale, 1861: 4)

b) 'The fox knows the scents of seven valleys (Lewis, 1974: 192)

Translation of the old languages requires the translator to be skillfully trained, to have good cultural knowledge. Hopefully, by possessing such broad pertinent cultural knowledge , the translator can comprehend the original text well and translate it correctly.

The art of translating old languages, we believe, requires, in addition to the above qualities, that the translator must have enough language knowledge in the old SL as well as a good command of language knowledge in the present TL. Such knowledge includes grammar, vocabulary, phonetics and punctuation.

Languages continually change over time. New words or expressions are being added while others are left out or start to be used with different meanings. Consequently the old language is replaced with a new one. One example is that of Shakespearean English as compared with the English of the present. Similar changes still occur even in the present day languages. Consider the following: Once the word for 'cool' in colloquial English was used for the 'weather', but now it is used for many reasons, like to express the meaning for 'relaxed' 'excellent', 'smooth' etc. For example: 'She is totally cool and easygoing', 'This is a really cool setup!', 'This stuff is so cool. I am just floating' (Spears, 1975: 87) etc. Similar changes or innovations exist for other languages too. For instance, once the word for 'uchmaq ' in old 
Turkic languages was a noun meaning 'paradise', but now it is only used as a verb meaning 'to fly somewhere'. As for the words like 'aytmaq' - (narrate), ' esen' - (healthy), 'tanuq' (witness), 'yom' - (good tidings), they are no longer used in the modern Turkic languages now. (Dəmirçizadə, 1959: 143)

In old Arabic language, unlike old Turkic languages, once the letters in Arabic included no dots in the past before Islam, and adding dots to the language became one of the first innovations in the Arabic language history. Today, it is very easy to distinguish consonant letters from one another in Arabic (Wiki Books, 2012)

As for the Persian, this language switched to Arabic script after Islam and $50 \%$ of today's Persian lexicon is of Arabic origin, not only in writing but also in everyday speech (Language Study, 2012). For example, today, Persians use the word 'Salaam' to greet people. However, before Islam, they used the words 'Rouz-e-gar Neek' and 'Dorood' for greeting in Persian. (Iran Chamber Society, 2012).

So, after considering all these difficulties in old languages, to say that translators should learn old language first before they start translation may not be realistic because it usually takes a long time to learn a language and then start a translation! If any language learner started translating, all language learners would be translators. Not every person who learns a language also translates well. Accordingly, we consider that it is better to choose those who already have enough knowledge about the old language.

Besides, 'knowledge of the old language', of course, includes familiarity with the idiomatic phrases. There are some mistranslated idioms that we would like to share. For example, this proverb which is mentioned in the book of Dede Korkut was lost from the text during its translation into English and was used instead as if it was a typical sentence rather than a proverb. The well known proverb 'They say the neighbor's due is God's due' was translated as 'Is this not a neighbor's duty?' (Shikhbabayev, 2009: 79) like a question but not a proverb!

Certainly most think that it is not possible to translate any text perfectly and therefore accept such misrepresentations to be quite natural. However we think that translators should not ignore words or expressions written in old language just because it is difficult to research them or discover their actual meanings at the time of their writing. Accordingly, we consider that translators should pay more attention to old language than they pay attention to modern languages. While such consonantal alphabets is living and modern, they will require more study in order to fully understand and appreciate. 
Another concern is the translators' lack of familiarity with writing rules of old languages which that were completely common for people living in the past. Unfortunately, some translations are done by those individuals who are only very well-informed in target language and not able to translate the intended meaning just because they are not familiar with the numerals, punctuations, marks or signs of source languages which had been applied in the past. So, each and every translator intending to translate old languages (Arabic, Persian and Turkic languages written in Perso-Arabic script) should learn writing rules of those languages well enough before beginning to translate it or as was noted earlier, such translations should be translated by those who already have the above mentioned skills.

Old languages report to us about the civilization and the culture of nations. Translation and history of translation has shown that by making any small mistake in the text it is quite easy to depict a civilized nation or person as uncivilized, or vice versa. One example of such a mistake, is the investigation led by Azerbaijani researcher Konul Huseynova (Shikhbabayev, 2009: 9) in which she discovered a contradiction in the translation by W. S. Walker. She noted the fact that as a result of a single mistake in the first English translation of the book of Dede Korkut from old Turkic into English by W. S. Walker, in which the brave man, King 'Kazan', who is highly respected among Turkic speaking people, is described as a baby killer and a murderer. Consequently this mistake left a negative impact on readers about Kazan and Turkic kings. What was the cause of that expression being understood incorrectly?

The translator rendered the word for 'falcon' (a bird) as a 'baby' in the chapter of 'The Sack of the House of Salur Kazan.' According to the Turkic tradition the killing of a falcon which belongs to the enemy simply means to start a fight against them. The word 'toğan' with the first letter 't' in Turkic language means a 'falcon' but the translator understood it wrongly and translated it as a 'doğan' with the first letter 'd' which means 'to give birth to a baby'

Let's see the translation by W. S. Walker:

'Then let me reach the infidel,

Kill all his newly born.

Let me wipe off the blood with my sleeve from my forehead.

If I die for your sake let me die'

Translation by Geoffrey Lewis:

'I shall go to the unbeliever,

I shall rise again and kill,

I shall wipe the blood of my forehead with my sleeve.

If I die I shall die for your sake' 
Translation by Paul Mirabile:

'I shall go to the infidel.

Again I shall kill your falcon-enemy,

I shall wipe the blood of my forehead with my sleeve.

If I ma killed, I shall die for your sake'

So it is clear that to kill a bird is one thing, to kill a baby is another and the acts must never be mistaken for each other or even compared. Herein a small mistake caused a big problem and disgraced the King Kazan who still has a high reputation and is respected by Turkic

We can consider that mistakes like that are connected to the lack of knowledge of the source language and the culture that translator translates to the modern, target language. Fortunately, in later translations (Lewis, 1974; Mirabile, 1991) of the legend called the book of Dede Korkut the same mistake was not repeated.

Likewise, Andrew Harvey, teacher of mystic traditions and the author of the audio book called 'Gay Mysticism' locates Rumi alongside Plato and Walt Whitman, as a 'gay mystic' (Enfolding, 2012). Besides, a great spiritual instructor Shams Tabrizi was condemned homosexual acts by some people for his spiritual view of life (History of Islam, 2012) due to their lack of familiarity with the essence of Persian Sufi poetry and the culture of that period (Darul'Masnavi, 2012).

On the other hand, there are unfortunately some translators that they completely remove a sentence from a text rather than make any further effort to translate it. Even worse, many don't leave a note about the exclusion of the words or expressions from the text. One example of this, is the sentence 'May Allah bring you joy within three days' which is mentioned in the chapter of 'The Story of Bamsi Beyrek, Son of Kam Büre' in 'the book of Dede Korkut' (Shikhbabayev, 2009: 89) but was completely removed from the text during the translation process. However, one of the three translators, W. S. Walker, managed to preserve the same meaning in the text and translated it successfully. For example:

Have you some bread in your reed basket?

'For three days I have traveled ceaselessly. Feed me!

May Allah bring you joy within three days.

(W.. S. Walker)

Have you any bread in the crock?

'Three days have I journeyed; give me to eat.'

(.....not translated.....) 
(Geoffrey Lewis)

Have you any bread from your leather cloth covering?

'I have been on the road for three days; feed me!'

(.....not translated.....)

(Paul Mirabile)

Another sentence 'Your lovely mane is similar to silk' (Shikhbabayev, 2009: 116) was left out in the same way by P. Mirabile in that the same chapter. However, other two translators could manage to translate it successfully without leaving it out.

Your little eyes are like two precious stones that shine at night.

(.....not translated .....)

(Paul Mirabile)

Your lovely eyes shine like two torches in the dark.

Your lovely mane is similar to silk.

(W. S. Walker)

Your dear eyes are like two glowing jewels,

Your dear mane is like rich brocade,

(Geoffrey Lewis)

Some translators behave as though some sentences or words in old manuscripts are unnecessary and that accordingly, there is no need or advantage to translating them. Besides, we consider that translators are required to give it in a note when a word or phrase is difficult to understand or translate and they should not leave them out neither partly nor completely, and they should not even abbreviate the text while it is repetitive or difficult to understand. As in the next example, the expression for 'drawn by scribes' (Shikhbabayev, 2009: 116) was left out in the translation partly by W. S. Walker, in the chapter of 'The Story of Kan Turali, Son of Kanli Koja' in the book of Dede Korkut.

'My girl with narrow mouth no larger than an almond shell,

My black-browed one (.....strongly abbreviated......)

(W. S. Walker)

'Too tiny your mouth to hold twin almonds.

Your black brows are like lines drawn by scribes'.

(Geoffrey Lewis)

'My narrow-mouthed one who cannot contain two almonds.

My black-browed one, drawn from the painters' pens'.

(Paul Mirabile) 
In the next example, the translator, G. Sale reduced five verses to three in number when translating Koran from original Arabic into English and used semicolons instead of numbers. For example;

'Have you not seen how your Lord dealt with the masters of the elephant? Did he not make their treacherous design an occasion of drawing them into error; and send against them flocks of birds, which cast down upon them stones of baked clay; and translate them like the leaves of corn eaten by cattle' (Sale 1861: 499-500)

Let's see the correct translation of the same chapter in the translation of Muhammad Taqi-udDin Al-Hilali and Muhammad Muhsin Khan:

1. Have you not seen how your Lord dealt with the owners of the elephant? (The Elephant army which came from Yemen under the command of Abraha Al-Ashram intending to destroy the Kabah at Makkah) 2. Did He not make their plot go astray? 3. And He sent against them birds, in flocks, 4. Striking them with stones of Sijjil (baked clay) 5. And He made them like (an empty field of) stalks (of which the corn has been eaten up by cattle) (Al-Hilali, 1998: 851)

However, G. Sale managed to preserve the correct order of the verses in the other chapters of the book when translating. Let's see his translation:

For the uniting of the tribe of Koreish; their uniting in sending forth the caravan of merchants and purveyors in winter and summer; let them serve the Lord of this house; who supplies them with food against hunger and has translated them secure from fear.' (Sale, 1861: 501)

And now, see the translation by Muhammad Taqi-ud-Din Al-Hilali and Muhammad Muhsin Khan.

1. (It is a great Grace and Protection from Allah)for the taming of the Quraish, 2.(And with all those Allah's Grace and Protection for their taming, We cause) the Quraish caravans to set forth safe in winter (to the south) and in summer (to the north, without any fear), 3. So let them worship (Allah) the Lord of this House (the Kabah in Makkah), 4. He who has fed them against hunger, and has made them safe from fear. (Al-Hilali, 1998: 851)

We consider that translation of old languages should not be an individual effort, but rather should be a team effort involving both scholars and translators who have theoretical and practical knowledge of old languages as well as a strong background in the culture and history of those languages. Hopefully, such a team sitting and working intensively together should be able to overcome such difficulties and problems that occur in translation of old languages and any misunderstanding or misinterpretation related to the culture encountered in the text could be solved by this functional group. 


\section{Conclusion}

Definitely, difficulties are expected when translating a language especially a language that is not presently used or completely forgotten. Besides, some crucial aspects of translation like accuracy and efforts to preserve the originality of the source language meaning when translating the text, be it either old or modern language have always been difficult regardless of what language you are translating to or from or how well the translator experienced is. However, we should accept the fact that as long as people write a language in completely different alphabet, undoubtedly difficulties will occur or even worse, it will double the difficulty. So we purposively selected some incorrectly or poorly translated words and expressions as an example in each three book translated by W. S. Walker (Walker, 1972), Geoffrey Lewis (Lewis, 1974) and Paul Mirabile (Mirabile, 1991) based on other three copies (Ergin, 1994; Comşidov, 1999; İsaxanl1, 2002) of one of the legendary and historical books of the Turks, the book of Dede Korkut which was written in the old Turkic language with a consonantal alphabet, which is presently stored in the Vatican, Berlin and Dresden Museums and as well as The Alcoran of Mohammed (Sale, 1861) which was translated into English immediately from the original Arabic by G. Sale, which is presently stored in the Southern Regional Library Faculty of University of California, Los Angeles and some other sources (Tourage, 2005; Enfolding, 2012; Darul'Masnavi, 2012) about Rumi.

To sum up the research, we advise a translator intended to translate old languages written in Arabic script to become aware of difficulties and suggestions which suggested here before they start translating.

\section{Difficulties}

(1) The most evident difficulty in translating old languages written in Arabic script is the alphabet itself including the writing rules of those languages.

(2) Differences in cultural practices between the old and the new culture of the original text.

(3) The phonetic system of the languages. Absence of vowel signs in Arabic, Persian and old Turkic especially in the professional form of the language confuse readers.

(4) The translators' lack of familiarity with Arabic script types. Taking into account that old Turkic language was used with Arabic script types like Kufic, Naskh, Thuluth, Ta'liq, Nasta'liq, Riq'a, Diwani and others (Classic Arabic Script Types, 2012).

(5) Some translators intending to translate old languages into English attempt to translate old languages on their own without seeking any advice or help from others and avoid 
group working. Accordingly, translation of old languages seems difficult or insolvable at first glance.

\section{Suggestions}

(1) The translator should make it clear whether the manuscript is the copy or the original.

(2) In the event original doesn't exist, a translator should try to obtain all available copies or even the copies of the copies.

(3) The translator must attain all necessary knowledge about the old SL and should have a good command of present TL.

(4) It would be better if a translator is chosen from among who is well aware of the old language or already experienced in that type of translation.

(5) The translator should be more careful while translating old languages and must avoid making any small mistake accept that translation of old languages bears importance for the culture of people.

(6) The translator should try to seek the best fitting meaning of the word of the original and not remove it instead in order to avoid wrong translation.

(7) The translator should report what they have omitted in the original text no matter how difficult the language is and give them in a note on the pages of their translation.

(8) The translator should neither abbreviate nor extent the meaning in sentences when it is repetitive or looks long.

(9) The translator should not play on the words or phrases translating the same word in a different way in the same translation.

(10) In the event an available professional translator is hard to identify, it is better to hire someone who is rather experienced in SL than being a professional in the TL.

Surely, such skillful and reliable translators are especially needed today. So many societies with their differing religions and cultures must live more closely as a global community than ever before. Such accurate translations can help bring them together and form friendships while teaching some traditional values of each. This type of high quality and correct translations can only but help to bring peace and solidarity in this multicultural world.

\section{References}

Al-Hilali, Muhammad. Muhsin Khan, Muhammad. (1998) 'The Noble Quran English Translation of the meanings and Commentary'. Madinah. King Fahd Complex Arabic Calligraphy. (2012). Artwork by Mokhtar El Baba and Kamel El Baba Classic Arabic Script Types. Retrieved from http://www.arabiccalligraphy.com/classic-types 
Comşidov, Şamil. (1999). Kitabi-Dadam Qorqud. Bakı, Elm

Darul'Masnavi of the Mevlevi Order. (2012). A Reply to Misunderstandings about Rumi and

Shams by Ibrahim Gamard. Retrieved from http://www.dar-al-masnavi.org/rumi-shams.html Dəmirçizadə, Obdüləzəl. (1959). Kitabi-Dədə Qorqud dastanının dili. Pedaqoji institutların tələbələri üçün tədris vəsaiti. Bakı. APİ

Enfolding. (2012). Framing Rumi's Ecstasy of Being. Retrieved from http://enfolding.org/framing-rumis-ecstasy-of-being

Ergin, Muharrem. (1994). Sözlük, Dede Korkut Kitabı II. Indeks-Gramer, Erzurum, Tipkıbasım

Hatip, Abdulaziz. (1999). Mülk. Nebe ve Saf surelerinin tefsiri. Baku. Baku State University Press

History of Islam. (2012). Maulana Rumi Contributed by Ibrahim Gamard. Retrieved from http:/historyofislam.com/contents/the-classical-period/maulana-rumi

Iran Chamber Society.(2012). Modern Persian. Retrieved from http://www.iranchamber.com/literature/articles/persian_parsi_language_history.php İsaxanl1, Hamlet. Kitabi-Dədəm Qorqud Aşiqi. Bak1, Xəzər Universitəsi Nəşriyyatı 2002 Language Study. (2012). Are Arabian and Persian Related?. Retrieved from http://suite101.com/article/what-to-know-about-arabic-vs-farsi-a77390

Lewis, Geoffrey. (1974). The Book of Dede Korkut. England, Penguin Books Mirabile, Paul. (1991). 'Legends of Dede Korkut'. Istanbul, Inkilab Kitab Evi Spears, Richard. (1975). NTS's dictionary of American slang and colloquial Expressions. Third edition. Chicago. NTC Publishing Group Shikhbabayev, Nusrat. (2009). Analysis of Dede Korkut English Translations. Doctoral dissertation, Khazar University

Sale, George. (1861). 'The Koran: Commonly called The Alcoran of Mohammed'. Southern Regional Library Faculty of University of California. Los Angeles

Tourage, Mahdi. (2005). The Hermeneutics of Eroticism in the Poetry of Rumi. Comparative study of South Asia. Africa and the Middle East. Dule University Press. Vol. 25. No. 3.

Warren, Walker. Sumer, Faruk. Uysal, Ahmet. (1972)The Book of Dede Korkut, London, University of Texas Press

Wikipedia. Abjad. (2012). Retrieved from http://en.wikipedia.org/wiki/Abjad Wikipedia. (2012). Languages using the Consonantal alphabets, Retrieved from http://en.wikipedia.org/wiki/Persian_alphabet 
Wiki Books. (2012). Retrieved from Arabic/Some history.

http://en.wikibooks.org/wiki/Arabic/Some_history

'Several people read this article during various stages of its development. The author would like to thank Shirley Stanley, Yaqut Bakhshaliyeva, Sevda Shikhbabayeva and the anonymous reviewers for their critiques and suggestions. 